\title{
Transition Theory in Decision Making for Regional Peace amongst Disputing Nations in Event of Nuclear Radioactive Contamination in South China Sea
}

\author{
Ahmad Faizul Shamsudin (Corresponding Author) \\ Faculty of Management and Information Technology, \\ University Sultan Azlan Shah, Bkt. Chandan, 33000 \\ Kuala Kangsar Perak, Malaysia \\ Tel:+60172203967 E-mail: afaizuls@usas.edu.my \\ Mohd Husin Abdullah \\ Faculty of Management and Information Technology, \\ University Sultan Azlan Shah, Bkt. Chandan, 33000 \\ Kuala Kangsar, Perak, Malaysia \\ Tel:+6037732323 E-mail: mhussin@usas.edu.my
}

\begin{abstract}
Regional peace in the South China Sea, despite claimants by many nations is often transitory ranging from the search for survivors of MH370 tragedy to creating supposedly common and sustainable fishing grounds. This study explores transition theory which explains the shifting of a state to a viable end-state with incremental steps to achieve regional peace in a scenario of an environmental tragedy from nuclear radioactive contamination in South China Sea. The transition theory uses Multi-Level Perspectives (MLP) framework which combines both qualitative context and quantitative process in one integrated decision making framework. The decision making outcomes from the MLP can be on fairness under competition and cooperation for the common welfare gains. It can also be a decision-making outcome on equity with respect to each participating actors' willingness to pay for the precautionary or damage abatement costs. A survey was conducted amongst 'actors' $(\mathrm{N}=20)$ as respondents on an assumed nuclear power plant radioactive contamination in the South China Sea region. The study shows that decision-making outcomes for equity and fairness by using transition theory in the MLP framework may lead to higher precautions that may be unaffordable to some of the disputing nations in South China
\end{abstract}

Sea. However, technological innovations in long term radioactive contamination damage abatement technology which lead to lower precautions may provide the 'common ground' amongst the disputing nations to vouch for a more permanent regional peace.

Keywords: regional peace, transitions, multilevel perspectives

\section{Introduction}

The search for MH370 in March 2014 might have created a temporal regional peace amongst disputing nations in South China Sea in order to search for the survivors. It was a classic maritime cooperation between Malaysia, Vietnam, China and Phillipines. Singapore, Thailand and the United States are also among the claimants of parts of South China Sea's resources and islands (Hayton, 2014). Likewise, an unprecented environmental tragedy from radioactive contamination to marine flora and fauna in South China Sea may bring the nations together again. However, the decisions by disputing nations to cooperate may not be on the similar emergency premise as in the MH370 tragedy.

The question of regional peace in the South China sea is often a transitory concern. In the 
surrounding areas of Suth China Sea, there are about 500 million people who are also great consumers of fish. Fishing fleets from the surrounding countries are depleting fishing resources in the Spratlys (Zhang, 2012). The approach to resolve conflicts of common fishing ground for regional peace in South China Sea was mooted as early as 1990 in the first workshop on "Managing Potential Conflicts in South China Sea" (McManus, 1994). It was based on the Djalal-Townsend-Gault initiatives in 1989 with the aim to seek common ground for cooperation and trust-building between claimants. Thus, a giant fish nursery as a 'peace park' in the Spratlys was initiated from 2002 to 2008 to create sustainable fishing grounds (Djalal, 2002; Djalal \& Townsend-Gault, 1999).

Another regional concern on peaceful cooperations amongst nations around South China Sea including emerging economies of Malaysia, Thailand, Vietnam, Indonesia and Phillipines is whether free international trade may weaken the effectiveness of national environmental regulations to address an environmental crisis of a possible nuclear radioactive contamination (Grossman \& Krurger, 1991). Trade liberalisation would encourage the shift of carbon-intensive industries to countries without carbon dioxide reduction targets such as China, Malaysia, Thailand and Korea. In contrast, the factor endowment hypothesis suggests that energy use is complementary to capital, so that emissions are associated with capital-intensive industries. Trade liberalisation will further concentrate these capital-intensive (such as nuclear energy) industries in relatively capital-abundant countries such as Japan and Korea (Kuik \& Gerlagh, 2003).

However, low-carbon trade liberisation may result in environmental tragedy with the choice of nuclear energy in the bio-sensitive region. The scalar and very long term damages to the South China sea environment such as possible widespread leakage of radioactive compounds from nuclear waste facility safety breach and nuclear power waste leakages can go beyond thousands of years with immeasurable risks and uncertainties (Tietenberg, 2006). An approach to assess this type of damage and the scientific uncertainties of such damages is called the 'precautionary principle' which is used for environmental and health protection for long term sustainability (Rafflesperger \& Ticker, 1999). Analogous to "innocent unless proven guilty", this approach is for the polluter "to undertake the task of proving" that the activity or the introduction of the product was not responsible for the damage suffered" (Ansari, Jamal \& Mustafa, 2006, p.30). Its fast and extensive acceptance in international legal instruments make it important within the international community. With the emergence of the 'polluter pays' principle and widespread acceptance of the axiomatic idea of 'sustainable development', the precautionary principle stands as one of the pillars in the area of environmental protection. Based on the Cartagena Biosafety Protocol 2000, the precautionary principle can be a tool for assessing societal damage in the local context with the premise; "where harm is imminent and beyond the limit of sustainability, the precaution principle should be made operative, unless the harm is of a trivial nature and sustainability of the environment and health are not impaired" (Ansari, Jamal \& Mustafa, 2006, p. 133).

The traditional command-and-control and emissions charge strategy previously has adversed political implications in the decision making (Titienberg, 2006). The transition theory, on the other hand, uses Multi-Level Perspectives (MLP) framework which combine both qualitative context and quantitative process in one integrated decision making framework (Grin, 2008). The MLP framework has slowchanging socio-political regime of societal values and ideology at one level. This may put pressure on the other level of heterogeneous social-technical regime with cultural, infrastructure and markets that would be prone to rapid changes such as regional environmental crisis. These regimes may generate incremental innovations which can protect technological 
niches and are market-driven. The decision making outcomes from the MLP can be on fairness under competition and cooperation for the common environmental good. It can also be a decision-making outcome with respect to each participating actors' willingness to pay for the precautionary or damage abatement costs. This paper explores these costs from transition theory perspectives for possible solutions of regional peace in event of major nuclear radioactive contamination to the marine environment.

\section{Transition Theory Approaches}

Previous transition concepts mainly look at the supply-side and the production of innovations (Etskowtz \& Leydesdorff, 2000; Malerba, 2002). They take the user-side for granted or narrow it down to 'the market' which functions as a neutral selection environment. Current studies in transitions not only involve industries, firms and technical knowledge, but also changes in user contexts and symbolic meanings (Geels, 2004). The problem with existing conceptual approaches of energy policy such as classical econometrics (Hope, 2006) and environmental economics (Weyant, 1999) is that they are not capable of taking into account actors' heuristics with worldviews and values. The values could be cultural based and transcendental forms of beliefs (Schwatrz \& Bardi, 2003; Rokeach, 1973) that are found to be among the major elements in the socio-political landscapes (Rotmans, Kemp \& van Asselt, 2001). Transitions to sustainability which require changes from one systems to another may involve these values for cultural meanings (Rotmans, Grin, Schot \& Smits, 2004; Elzen, Geels \& Green, 2004). Different conceptual perspectives of transitions (Geels, 2004) range from evolving technological regimes (Nelson \& Winter, 1982), techno-economic paradigm shifts (Freeman \& Perez, 1988) and socio-technical theories to multi-level perspective (MLP) framework of transitions (Grin, 2008).
The transition theory using the qualitative evolutionary economic theory (Nelson \& Winter, 1982) would consider human beings as having limited cognitive capacities in the midst of uncertainties and intricacies of the realworld. Accordingly, humans tend to use rules and cognitive frameworks to make a sense of the real world which are shared within groups. Thus technocrats as 'actors' are guided by cognitive rules for particular directions that may lead to the 'right' technical choice. However, such evolving regime may not favor new technologies replacing old technologies (Geels, 2004). This can be seen from technological preference for less efficient but relatively high carbon low capital cost facilities diesel generators to cleaner but higher capital cost of hybrid diesel-wind turbines in remote Malaysian, Pulau Layang Layang in the Spratlys (Shadzli \& Ahmad Faizul, 1992). Quantitative technological preference may be explored to overcome this shortcoming in evolving regime changes.

A quantitative approach for transition theory involve historical clusters in the shifts of technoeconomic paradigms. These are clearly seen from the post-war wireless communication to the current broadband internet technology. This approach uses long-wave theory (Freeman \& Perez, 1988) where several 'waves' were observed beginning from a paradigm that emerged in a world that was still dominated by an old communication paradigm (monopoly) to the current new techno-economic internet paradigm (sharing). This involves major changes to overcome the initial mismatch of innovations (as in the initial debut of mobile phones). However, long-wave theory does not describe how new technologies emerge involving the combination of macro-aspects such as economic growth with processes at the micro-level and real-life activities of actors involved in developing new technologies. Long-wave theories also suffered deterministic notions as recent works (Dryzek, 2005) focus on interactions between technology and qualitative aspects of economy, politics and culture. 
Another qualitative approach in transition theory using the transformation frame focuses on the actors' groups, their activities, perceptions and rules which guide their changing perceptions. This frame does not shift suddenly but step by step. Frames are modified on the basis of real experience, leading to new technological functions. Because these new understandings and practices are improvised out of old ones, the dynamics would be in the transformation process. This is shown by the changes in the computer regimes (Van den Ende \& Kemp, 1999) such as from a regimented masterclient computing to peer-to-peer distributive "free-for-all" internet users. In socio-technical literature the transformation frame involves networks of heterogenous elements with linkages and elements requiring continous reproduction, maintenance and repair such as transformations in seamless webs (Von Meier, 1994). Transformation frames mainly focus on the early phases of new technologies in the "green field" or "uncharted territories" scenario. On hindsight, transformation frames pay less attention to what happens when technologies are on new and unproven grounds. Instead, they should be more concerned about technological crisis, diffusion and economics such as the quantitative effects of electricity sales price and market share.

Current transition theory using the evolving regime does not consider the changing technology preference. The techno-economic regime does not look at the economic competition between old and new technologies. The transformation frame lacks emphasis on effects of pricing, performance and user preferences. The combination of both qualitative and quantitative approaches in transition theory is desired. Thus a multi-level perspective (MLP) approach is proposed. This approach can generate more heuristics rules based on natural assessments and biases (Gilovich, Griffin \& Daniel, 2002) and distinguish phases in system innovations and their integration (Grin, 2008).
The changes on the slow moving socio-political landscape regime or level may put pressure on the socio-technical regime. Climate change, for instance can put pressure onto trade liberisations between nations in South China Sea. Broad cultural changes in values and political wills may also create pressure on the socio-technical regime (Elzen, Geels \& Green, 2004) such as the Fukushima post-tsunami nuclear disaster that incurred huge social and environmental burdens in Japan until today. The pressures exerted onto the social-technical regime may be shown by the socio-political landscape and social technical regimes that would seem to exist in two dynamic planes, the earlier is slow moving while the latter is fast moving. While both the socio-technical regime and the sociopolitical landscape may generate incremental technology innovations, in reality though, radical changes in the technological niches regime are generated from incubation rooms that are protected from normal market selection (Schot, 1998). The relationships between the three transition perspectives (socio-political landscape, social-technical and technological niches regimes) and their dynamic multi-planes or multi-levels connection hence need to be rationalized. This can be further explained by the previous transition from highly regulated national control to less regulated privatisation of economic exploitation of fisheries in South China Sea. As a result, the number of 584,000 fishing operators in 1980 had risen to 1.8 million operators in 2002 registered in Phillipines (Fao, 2005). The socio-political agenda of actors (technocrats with engineering and economic knowledge) exerted regulatory changes through unilateral ban by China for fishing in North of Spratlys (Xinhua, 2013) that may subsequently create pressures to social technical regime such as fishermen's choices for bigger engine fishing boats (Berkhout, Smith \& Stirling, 2004).

Decision-making based on the current environmental issues indicated that people generally value losses much more than they do on gains (Knetsch,1999). In terms of losses, it could be the maximum sum they are willing 
to pay (WTP) that will lead to fully equivalent values except for small differences due to income or welfare effects. In previous studies, it was found that WTP was the conservative measure. This would provide the justification for the current universal practice of using WTP measure to value losses as well as gains. A recent definition of willingness-to-pay (WTP) is "the reciprocal of the marginal rate of substitution between one's income and other's income" which gives WTP a public choice notion (Cox, Friedman \& Sadiraj, 2008). It was for this reason that this study adapts the WTP measure for decision-making outcomes. The dynamic multi-level perspectives of transitions as described earlier may address the decisionmaking problem through a series of cues (links between regimes) that could finally lead to decision-making outcomes as the willingnessto-pay (WTP) for precaution levels (defined as the sum of damage abatement costs) in the event of a major nuclear radioactive contamination as illustrated in Figure 1 below.

In the multi-level perspectives framework for transition analysis as in Figure 1 below, the policy outcome $\mathrm{Hc}^{*}(+\infty$, zs ) opt (optimal total costs to society) as for precaution levels (such as the impact of nuclear radioactive contamination ) is 'pressured' by the sociopolitical landscape regime of heuristics of worldviews and values of local community (Kemp, Rip \& Schot, 2001) depicted by the sum of societal cues, $\sum(\xi) n$ which can include worldviews and values. The decision-making outcomes are also 'pressured' by technological niches regime in terms of innovations or the sum of technological cues $\sum(\mathrm{Pk}) \mathrm{n}$ or the protected development of niches and incentives for use of damage abatement technologies (Kemp, Schot \& Hoogma, 1998). During negotiations for decisions on compensation amount for example, actors are more willing to concede allowances to cover direct costs than they are to accept proposals of concessions to cover lost opportunities (Borges \& Knetsch, 1997). Other studies also indicated the promise of greater understanding of the characteristics of trade- offs in decision making to be more acceptable (Knetrsch, 1990).

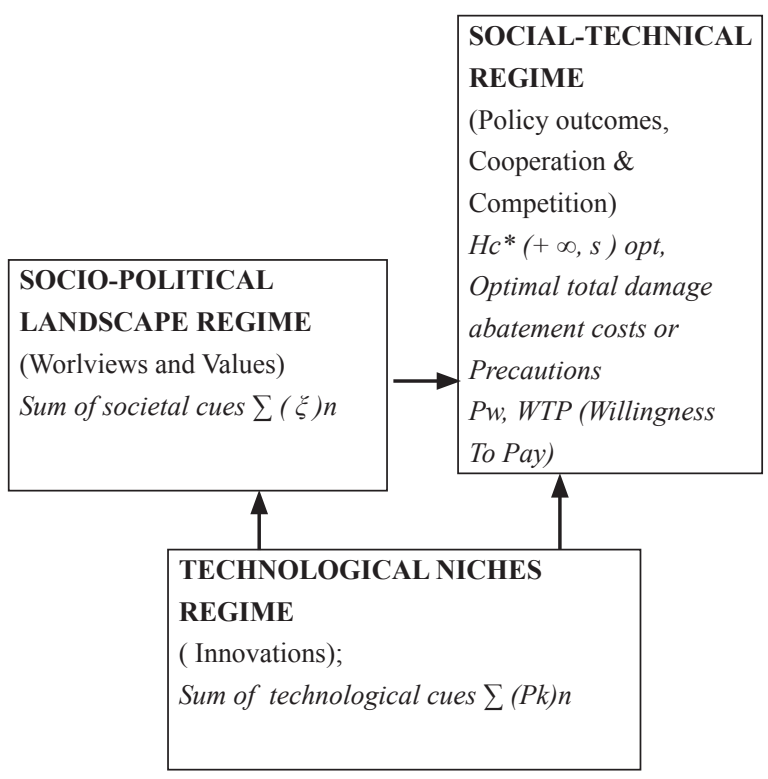

Figure 1: Transition regimes in the Multi-Level Perpectives (MLP) framework on precaution levels

The decision outcomes of equity and fairness for innovative technologies (Gamboa, Munda \& Russi, 2008) can be important to the social context of future burdens to the environment and society. Future burdens include the problem of increased costs of living to individuals and the costs of mitigating environmental damages. The equity outcomes may be viewed as costs to society that may incur future welfare losses such as reduced net income levels and GDP growth (Hope \& Newsbury, 2009). The other outcome is for fairness which emphasizes the precautionary principles (the notion that the polluter pays), reported in current studies on costs of abating long term damages to society and environment in the event of a major nuclear disaster. The precaution level may indicate the actors' willingness to accept a 'fair' compensation between the minimum sum of costs of precaution and the maximum costs of unabated damages. That is, the affordable costs to nations that could pay for the damages and that the insurance would be able to underwrite the risks. 
In competition and cooperation, the decision for policy outcomes of optimising the total costs of damage abatement to society or precaution levels due to long-term damages in the event of a major nuclear radioactive contamination (such as the Fukushima nuclear power plant tragedy) may contribute to the environmental crisis resolution. Among actors, their competitive and cooperative biases may differ on the equilibrium or optimal cost sharing for pay-offs involving the precaution levels. This cost-sharing for levels of precaution can attain an optimal level between the minimum sum of costs of damages and the maximum costs of unabated damages (Titienberg, 2006). The choice for an optimal precaution level can combine the push and pull factors found in socio-political landscapes and technological niche perspectives (Knetrsch,1990). Thus, the willingness-to-pay for cost sharing amongst the cooperating 'actors' (fs) for the optimal sum of the costs of compensation can be shown by equation 1 below, where the total costs of damage abatement technology to society is $\xi$.

$\mathrm{Hc}^{*}\left(+\infty, f_{s}\right) \mathrm{opt}=f\left\{\min \sum \mathrm{a}, f s, \mathrm{~b}, n, \xi\right\}$ [Equation 1]

Where, $\mathrm{a}$ and $\mathrm{b}$ are costs constants, $f_{s}$ is the fraction of actors who are cooperators and $n$ is the total number of actors. The attempt to attain the actors' willingness to pay for damages now to mitigate future societal costs may find the optimal level of precautions Hc*. Thus, decision-making outcomes with respect to individual's willingness-to-pay (WTP) for welfare loss (such as loss of income) may be and indicator of conflict resolutions. The "willingness-to-pay" is policy outcome $P w$ from the judgments on incentives and societal factors which can be,

$$
\begin{aligned}
& P w=f\left\{\left[\sum(\mathrm{Pk}) \mathrm{n}\right] \times\left[\sum(\xi) \mathrm{n}\right]\right\} \\
& \text { [Equation 2] }
\end{aligned}
$$

The sum of societal cues is $\sum(\xi)$ n such as actors' worldviews and values. Actors' choices for profitability $P w$ (e.g., WTP for fair precautions) are also influenced by the sum of intermediate variables of judgments on socio-political landscape, social-technical and technological niches regimes as shown by $\sum(\mathrm{Pk}) n$ mainly accrued from appropriate regional negotiations.

An approach to uncertainties in optimisation problems in determining the 'fair' or optimal precaution levels or the costs of nuclear damage abatement is to convert a single-objective problem to two-objective problem which should be considered as both feasible and robust (Jiang, Han, Liu, \& Liu, 2008). Thus, one objective of using heuristics is to determine the decisionmaking outcome of precaution level amidst the uncertainty of long term societal damages. The other objective is the use of heuristics to ascertain the 'fair' or optimal outcomes with the uncertainty of long term welfare losses. In some real-world problem though, the method of meta-heuristics or the "rules of rules" seem to dominate the current research (Grubb \& Newbery 2008). However, the heuristics that will be developed in this thesis will be based on the sets of rules derived from the proposed MLP transition framework. Heuristics to be derived may be patterns of biased judgments or can at the same time be based on rational estimates that both would represent the underlying processes of transitions. These seemingly intuitive (though could also be biased or rationale or both) rules are responses to questions about likelihood and predictions. "These are processes through which people make a variety of important and difficult real world judgments. The solutions (from heuristics) are thus (can be) serviceable (though) not exact or perfectly accurate."( Gilovich, Griffin \& Daniel, 2002, p. 56). The current literature reports two system models of heuristics namely the 'natural assessment' or the rationale and the 'cognitive miser' or the familiar rules. Transition heuristics may be formed from both of these rules. 
Tablel. The Actor's mean scores (means)

\begin{tabular}{|c|c|c|c|c|c|c|c|c|}
\hline hst & $\begin{array}{l}\text { WV } \\
\text { Econ omic }\end{array}$ & $\begin{array}{l}\text { IntrinsicV } \\
\text { Besuty }\end{array}$ & $\begin{array}{l}\text { Socal } \\
\text { Trnstorm }\end{array}$ & Wr Gain & Bene fits & Risks & Pretem & $\begin{array}{l}\text { Precaution } \\
\text { Level }\end{array}$ \\
\hline 1 & 7 & 8 & 8 & 3 & 2 & 8 & 2 & 1 \\
\hline 2 & 7 & 8 & 8 & 8 & 8 & 8 & 8 & \\
\hline 3 & 5 & 6 & 6 & 7 & 8 & 8 & 4 & \\
\hline 4 & 2 & 8 & 8 & 9 & 8 & 8 & 8 & \\
\hline 5 & 7 & 8 & 8 & 6 & 10 & 8 & 6 & \\
\hline 6 & 10 & 8 & 8 & 6 & 4 & 10 & 2 & \\
\hline 7 & 7 & 8 & 6 & 6 & 8 & 9 & 8 & \\
\hline 8 & 7 & 8 & 8 & 6 & 4 & 8 & 8 & \\
\hline 9 & 9 & 6 & 1 & 8 & 8 & 5 & 4 & \\
\hline 10 & 5 & 6 & 6 & 4 & 8 & 8 & 8 & \\
\hline 11 & 9 & 8 & 6 & 4 & 8 & 8 & 8 & \\
\hline 12 & 5 & 4 & 4 & 2 & 2 & 8 & 8 & \\
\hline 13 & 8 & 4 & 5 & 5 & 4 & 8 & 8 & \\
\hline 14 & 5 & 2 & 4 & 5 & 8 & 8 & 8 & \\
\hline 15 & 5 & 5 & 1 & 4 & 7 & 5 & 8 & \\
\hline 16 & 9 & 5 & 10 & 1 & 10 & 1 & 1 & \\
\hline 17 & 10 & 5 & 6 & 6 & 4 & 8 & 1 & \\
\hline 18 & 9 & 7 & 3 & 8 & 8 & 8 & 9 & \\
\hline 19 & 5 & 7 & 4 & 5 & 8 & 9 & 4 & \\
\hline 20 & 6 & 8 & 8 & 7 & 7 & 8 & 8 & \\
\hline Means & 6.85 & 8.25 & 5.7 & 5.4 & 8.5 & 7.55 & 5.95 & \\
\hline
\end{tabular}

Note: Inst: (Respondent), WVEconomic (Economic Worldviews), IntrinsicVBeauty (Intrinsic Value for Beauty), SocialTrsnform (Social Transformation in multifolds of social development), Global WlfrGain (Global Wellfare Gain increase of income), Benefits (perceived benefits), Risks (perceived risks), Preference (amage abatement technology choices), Precautions (levels from low to high).

TABLE 2a: Simulated HIGH biases for economic worldview and vahe of beaty

\begin{tabular}{|c|c|c|c|c|c|c|c|c|}
\hline hst & $\begin{array}{l}\text { Wh } \\
\text { Economic }\end{array}$ & $\begin{array}{l}\text { IntrinsicV } \\
\text { Besuty }\end{array}$ & $\begin{array}{l}\text { Social } \\
\text { Trnstorm }\end{array}$ & $\begin{array}{l}\text { Global } \\
\text { Wr Gain }\end{array}$ & Bene its & Risks & Prétmoe & $\begin{array}{l}\text { Precaution } \\
\text { Level }\end{array}$ \\
\hline 1 & 7 & 8 & 8 & 3 & 2 & 8 & 2 & \\
\hline 2 & 7 & 8 & 8 & 6 & 6 & 8 & 8 & \\
\hline 3 & 8 & 6 & 6 & 7 & 8 & 8 & 4 & \\
\hline 4 & 8 & 8 & 8 & 9 & 8 & 8 & 8 & \\
\hline 5 & 7 & 8 & 8 & 6 & 10 & 8 & 6 & \\
\hline 6 & 10 & 8 & 8 & 6 & 4 & 10 & 2 & \\
\hline 7 & 7 & 9 & 6 & 6 & 8 & 9 & 8 & \\
\hline 8 & 7 & 7 & 6 & 6 & 4 & 8 & 8 & \\
\hline 9 & 9 & 9 & 1 & 8 & 8 & 5 & 4 & \\
\hline 10 & 8 & 7 & 6 & 4 & 8 & 8 & 8 & \\
\hline 11 & 9 & 8 & 8 & 4 & 8 & 8 & 8 & \\
\hline 12 & 8 & 9 & 4 & 2 & 2 & 8 & 8 & \\
\hline 13 & 8 & 9 & 5 & 5 & 4 & 8 & 8 & \\
\hline 14 & 8 & 9 & 4 & 5 & 6 & 8 & 8 & \\
\hline 15 & 8 & 7 & 1 & 4 & 7 & 5 & 8 & \\
\hline 16 & 9 & 7 & 10 & 1 & 10 & 1 & 1 & \\
\hline 17 & 10 & 8 & 6 & 6 & 4 & 8 & 1 & \\
\hline 18 & 9 & 8 & 3 & 8 & 8 & 8 & 9 & \\
\hline 19 & 8 & 9 & 4 & 5 & 8 & 9 & 4 & \\
\hline 20 & 8 & 8 & 6 & 7 & 7 & 8 & 6 & \\
\hline Mears & 8.15 & 8 & 5.7 & 5.4 & 6.5 & 7.55 & 5.95 & 6.95 \\
\hline
\end{tabular}




\section{Methodology}

A survey was conducted amongst 'actors' of technocrats $(\mathrm{N}=20)$ as respondents on an assumed nuclear radioactive contamination in the South China Sea region. They were briefed on the problem and interviewed on the same day in one engineering facility. The actors' mean scores are shown in Table 1.

The Respondents Raw Data (RRD) were generated with normal, low and high biases to derive the actors' heuristics (biased worldviews and values). This is shown in Tables 2 a (high biases in worldviews and values) and Table $2 b$ (low biases in worldviews and values).

\section{Results \& Discussion}

The results of Pearson correlations showed positive relationships with precautions from the socio-political and social-technical regimes. The negative relationships were found with precautions from the risks and preferences of the technological niche regimes to precautions as shown in Table 2 .
The supervised learning test is conducted on sets of RRD with biases to verify the "Bias" heuristics in the transitions. This test uses simulated High and Low BIASED worldviews and intrinsic values in the RRD datasets to compute ( $\alpha$ ) for cue-relationships on precautions, as shown in Tables 3a, 3b and 3c.

The cue-relationships or (sequence of links between the regimes) depict the transition theoretical framework for decision-making outcome on precaution levels. Heuristics can be seen from the cue relations; biased economic worldview linearly related to social transformation $(\alpha=0.34)$, globalisation $(\alpha=0.64)$, perceived benefits $(\alpha=0.23)$, perceived risks $(\alpha=$ $0.51)$, convergence $(\alpha=-0.42)$ and precaution levels $(\alpha=0.20)$. The transition theory is used to compute the precaution levels.

The transitory changes can be seen by intrinsic value biases in the cues and compute the maximum or minimum values of precautionlevels. The results of heuristics of sociopolitical landscape perspectives (biased worldviews and intrinsic values) are shown. The transition framework responded to high biases of worldviews by the changes shown in the worldview's linear relations to social 
Table 2 : The resuls of calculations from above for correlation coefficients ( $a$ )

\begin{tabular}{|c|c|c|c|c|c|c|c|}
\hline WVEcon & IntsicV & SocTrns & Globaln & Bene fits & Risks & Preferno & Prcautn \\
\hline WVEcon & & 0.064 & 0.644 & -0.703 & -0.149 & -0.417 & 0.199 \\
\hline In tsicVal & & 0.340 & 0.288 & 0.229 & 0.197 & -0.129 & -0.064 \\
\hline SocTrnstm & & & -0.195 & 0.04 & 0.01 & -0.941 & 0.02 \\
\hline Globalzn & & & & 0.506 & 0.213 & 0.338 & 0.126 \\
\hline Bene fits & & & & & -0.354 & 0.112 & 0.385 \\
\hline $\begin{array}{l}\text { Risks } \\
\text { Preference }\end{array}$ & & & & & & 0.181 & $\begin{array}{l}-0.120 \\
-0.104\end{array}$ \\
\hline
\end{tabular}

TABLE 3a. The results ( $\alpha$ ) for real-world nomal distribution data are;

\begin{tabular}{|c|c|c|c|c|c|c|c|}
\hline WVEcon & htsid/ & SøcTrns & Globain & Bene fit & Risks & Prefer no & Prcautr \\
\hline $\begin{array}{l}\text { WVEcon } \\
\text { IntsidVal } \\
\text { SocTrnsin } \\
\text { Globalzn } \\
\text { Benefits } \\
\text { Risks } \\
\text { Preference }\end{array}$ & & $\begin{array}{l}0084 \\
0340\end{array}$ & $\begin{array}{r}0.644 \\
0.288 \\
-0.195\end{array}$ & $\begin{array}{l}-0.703 \\
0.229 \\
0.04 \\
0.506\end{array}$ & $\begin{array}{c}-0.149 \\
0.197 \\
0.01 \\
0.213 \\
-0.354\end{array}$ & $\begin{array}{r}-0.417 \\
-0.129 \\
-0.941 \\
0.338 \\
0.112 \\
0.161\end{array}$ & $\begin{array}{c}0.199 \\
-0.064 \\
0.02 \\
0.128 \\
0.385 \\
-0.120 \\
-0.104\end{array}$ \\
\hline
\end{tabular}

TABLE $3 \mathrm{~b}$. The results ( $\alpha$ ) from simulated low bia ses of world vie ws and values;

\begin{tabular}{|c|c|c|c|c|c|c|c|}
\hline WVEcon & Intsid/al & SocTmsin & Globalzn & Benefis & Rosks & Prefeence & PrectnLvi \\
\hline $\begin{array}{l}\text { WVEcon } \\
\text { Intsidval } \\
\text { SocTrnsim }\end{array}$ & & $\begin{array}{r}0.061781 \\
-0.03888\end{array}$ & $\begin{array}{l}0.248877 \\
0.018887 \\
-0.10779\end{array}$ & $\begin{array}{l}-0.13516 \\
-0.00683 \\
0.039287\end{array}$ & $\begin{array}{r}-0.06314 \\
0.021747 \\
0.010747\end{array}$ & $\begin{array}{r}-0.04459 \\
0.0671 \\
-094138\end{array}$ & $\begin{array}{r}-0.01833 \\
0.032853 \\
0.019009\end{array}$ \\
\hline $\begin{array}{l}\text { Giobalzn } \\
\text { Benefits } \\
\text { Risks } \\
\text { Preference }\end{array}$ & & & & 0.506031 & $\begin{array}{r}0.213278 \\
-0.35435\end{array}$ & $\begin{array}{l}0.338239 \\
0.112443 \\
0.180657\end{array}$ & $\begin{array}{r}0.126285 \\
0.384972 \\
-0.1196 \\
-0.10396\end{array}$ \\
\hline
\end{tabular}

TABLE 3c. The results ( $\alpha$ ) from simulated high biases of worl dviews and valves;

\begin{tabular}{|c|c|c|c|c|c|c|c|}
\hline & WVEcon & SocTmsfn & Gobalzn & Benefts & Risks & Prefeence & PrectnLvl \\
\hline $\begin{array}{l}\text { WVEcon } \\
\text { Intsidval }\end{array}$ & & $\begin{array}{l}-0.02461 \\
-0.21788\end{array}$ & $\begin{array}{r}0.43519 \\
0.011216\end{array}$ & $\begin{array}{l}-0.58075 \\
-0.05463\end{array}$ & $\begin{array}{r}-0.0689 \\
0.257489\end{array}$ & $\begin{array}{r}-0.22945 \\
0.032678\end{array}$ & $\begin{array}{l}0.129053 \\
0.132048\end{array}$ \\
\hline $\begin{array}{l}\text { SocTrnsin } \\
\text { Globalzn } \\
\text { Benefits }\end{array}$ & & & -0.11951 & $\begin{array}{l}0.039287 \\
0.506031\end{array}$ & $\begin{array}{l}0.010747 \\
0.213278 \\
-0.35435\end{array}$ & $\begin{array}{r}-0.94138 \\
0.338239 \\
0.112443\end{array}$ & $\begin{array}{l}0.019009 \\
0.128285 \\
0.384972\end{array}$ \\
\hline $\begin{array}{l}\text { Risks } \\
\text { Preference }\end{array}$ & & & & & & 0.160657 & $\begin{array}{r}-0.1196 \\
-0.10396\end{array}$ \\
\hline
\end{tabular}

Note: Globalzn (Global Welfare Gain) 
transformations (-0.22), global welfare gains $(0.44)$, convergence $(0.23)$, perceived benefits $(-0.58)$.

In developing heuristics, biased worldviews and values produce classification rules. Biased low values produce less rules (Table $3 \mathrm{~b}$ ) compared to biased high values (Table $3 \mathrm{c}$ ). However both biases produce less rules than the normal data (Table 3a). This indicates that biases may reduce complexities of supervised learning of datasets. The bias heuristics transitions may thus hold and will be explored further. Thus, such heuristics in the transition cues are demonstrated by the 'rules' between sociopolitical landscape (worldviews and intrinsic values), global welfare gains, environmental governance (perceived risks and benefits) etc. Nevertheless these rules assume equal importance of the judgmental cues which is not exactly true in the real world. The RRD yield correlations of these cues with unequal weights between these cues to derive heuristics. The actors need to be aware of the risks and benefits in their choices for the nuclear radioactive contamination abatement technology. The results of actors show their perceived risks and benefits to have small benefit-risks differentials in nuclear damage abatement technology. Small differential means that technological innovations are favored by all nations as the perceived benefits are higher than the perceived risks. The innovations may include low-costs and new designs, processes and procedures in damage abatement technology.

The transition regimes in the MLP framework yield equities that can be optimised from total costs to society with cues of environmental governance, convergence, social landscape, global welfare gains and social- transformation. As shown in the results of this study, the mean value for perceived precaution level of 6.95 (out of 10) indicated non-maximum precaution levels that actors's WTP (Willingness to pay) in event of major nuclear radioactive copntamination. The non-maximum precaution level indicates that actors are able to decide on levels of precaution that are between the minimum sum of costs of precaution and the maximum costs of unabated damages. That is, the cost to nations that it may not afford and the high insurance premiums needed to underwrite the risks.

The growing uncertainty of scientific evidences on the extent of major damages to society and environment, precautionary principles can be both pro-ecology and pro-society. The implication is that precaution concepts can be used as a democratic decision-making process on hazardous nuclear waste sites, clean ups and restoration activities. Claimant nations may have to adapt to these 'democratic' demands for a 'fair' and 'equitable' precaution level.

The contextual features in the local sociopolitical landscapes of actors' values and cultural lineage may adapt differently to global mechanisms of carbon abatement for climate change negotiations. The same may be the case for precautionary measures on future societal damages such as from lack of nuclear safety standards, hazardous nuclear waste disposal and terrorist prone nuclear fuel enrichment. Since the local socio-political landscapes regime such as social values, worldviews and political culture is defined in this study as the background, they may dictate the final outcomes of people's making decisions on risks, benefits and compensations. As an example, conflicting roles of worldviews on risk perceptions of nuclear power disasters against and for a nuclear waste facility in South China (nearer to South China Sea) are respectively found amongst the 'democratic' community in Hong Kong and the 'communistic' communities in mainland China. In contrast, in an information free and democratic society such as Finland, people's values and beliefs are important in a democratic decision making process for a nuclear waste facility location.

If a major accident occurred such as a nuclear reactor melt-down near the South China Sea, the 'polluter' nation should be in a position to pay for the total costs of compensations 
and additional safety measures demanded by the regional nations who are affected. Despite the possible amplification of costs, such precautionary approach may become more acceptable based on the increasing scientific uncertainty in assessing the risks of large and long-term damages. In reality, as more precautionary measures are taken, public may perceive additional reductions in damages obtained from those measures. Under uncertainty too, the extend of damages due to the tragic nuclear radioactive contamination may confront decision makers with the questions "how large should the margin of safety be defined? However, such approach may have to rely on 'public choices' in the region. Some claimant nations may find that public choices have significant normative content with the possibility of the citizen's (public) spirit in their preference for transition damage abatement technological options. The question is, will the nations around South China Sea be willing to make room for the perceived future risks in return for benefits based on the region's 'public spirit' or their respective visions embedded within their national worldviews and ideology? This may not be possible in the short-term at least. Thus, the transition regime of sociopolitical landscape may take too long to address the 'common ground' for a regional peace.

\section{Conclusion}

This study found that a decision-making outcome from the transition regimes of socio-political landscape and social-technical are focused on the equitable abatement costs that would incur future welfare losses such as reduced net income levels and GDP growth to the nations. The other finding on decision-making outcome from these transition regimes is fairness that emphasizes the precautionary principles (the notion that the polluter pays) on costs of abating long term damages to society and environment in the event of a major nuclear radioactive waste contamination. These precaution levels indicate the actors' willingness to pay for the costs and insurance to society that some nations (that are also claimants of South China Sea) could afford. Other claimant nations however, may not be able to afford these. Thus, regional peace may be a long way to go with these 'slow-moving' transition regimes.

The 'common ground' where all claimant nations to agree for regional peace, however is attainable as indicated by the negative relationships between precautions to risks and preferences of innovating damage abatement technologies in the technological niche regime. The perceived technological risks-benefits distances are small thus prompting innovations in the the long-term development of these technologies. This may bring the nations together again for a longerterm sustainable regional peace in finding innovative technological solutions to the very long-term nuclear radioactive contamination problem in the South China Sea.

\section{References}

Ansari, A. H., Jamal, P. and Mustafa, M. (2006), 'Meaning, Scope and Implementation of the Precautionary principle', in Hunud Abia Kadouf and Sharifah Zubaidah Aljunid (eds), Land use planning and environmental sustainability in Malaysia: policies and trends (pp.115-164). Research Centre, IIUM Kuala Lumpur.

Berkhout, F., Angel, D. \& Wieczorek, A.J. (2009). 'Sustainability transitions in developing Asia: Are alternative development pathways likely?'International Journal of Technological Forecasting \& Social Change, Vol. 76, 215-217, Elsevier.

Haton, B. (2014). The South China Sea - The Struggle for Power in Asia, Yale University Press, New Hacen and London.

Borges, B. F. J. \& Knetsch, J. L. (1997),' Valuation of gains and losses, fairness and negotiations ', International Journey of social economics, Elsevier 
Cox, J.C., Friedman, D. and Sadiraj, V. (2008). Revealed Altruism, Econometrica, 76(1), 3169.

Dragun, A., K. \& Jakobsson, K., M. (1999), 'Environment, Equity and Welfare Economics'. (eds.) Dragun, A.,K. \& Jakobsson, K.M., Sustainability nd Global Environmental Policy, Edward Elgar, pp.179-192. Cheltenham, UK,

Dryzek, J. (2005), The Politics of the Earth, Oxford: OU

Elzen, B., Geels, F.W. \& Green, K. (2004). System Innovation and the Transition to Sustainability, Edward Elgar, Cheltenham, UK.

Etskowtz, H., \& Leydesdorff, L. (2000),'The Dynamics of Innovation: from National Systems and "Mode 2" to A Triple Helix of UniversityIndustry- Government Relations', Research Policy, 29(2), pp.109-123.

Fao, (2005), 'Phillipines, Fishery Country Profile', FAO UN Report Nov. 2005.

Freeman, C. \& Perez, C. (1988). 'Structural Crisis of Adjustment, Business Cycles and Investment Behavior', in Giovanni Dosi, Chris Freeman, Richard Nelson, Gerald Silverberg and Luc Soete (eds), Technical Change and Economic Theory, pp. 38- 66. London: Printer.

Geels, F. W. (2004), ' Understanding System Innovations: A Critical Literature Review and A Conceptual Synthesis ', in B. Elzen, F.W. Geels \& K. Green (eds), System Innovation and the Transition to Sustainability, pp. 19-45. Edward Elgar, Cheltenham, UK.,

Gilovich, T., Griffin, D. \& Daniel (2002). Heuristics and Biases - The Psychology of Intuitive Judgment, Press Syndicate of the University of Cambridge, UK.
Grin, J. (2008). 'The Multi-Level Perspective and Design of System Innovations' in Managing the Transition to Renewable EnergyTheory and Practice from Local, Regional and Macro Perspectives, (eds.) Jeroen C.J.M. van den Bergh \& Frank P. Bruisma),Edward Elgar, Cheltenham, UK.

Grossman, G. M. \& Krurger, A. B. (1991), "Environmental impacts of a North American Free Trade Agreement," Cambridge: National Bureau of Economic Research Working Paper.

Grubb, M. \& Newbery, D. (2008), "Pricing Carbon for Electricity Generation: National and International Dimensions", (eds.). Grubb, M, Jamasb, T. \& Pollitt, M. G., Delivering a low-carbon electricity systemtechnology, economics and policy, pp. 31-63. Cambride University Press, New York.

Djalal, H. (2002), Preventive Diplomacy in South East Asia: Lessons Learned, Jakarta.

Djalal, H \& Townsend-Gault, I. (1999), 'Managing Potential Conflicts in the South China Sea: Informal Diplomacy for Conflict Resolution', in Chester A. Crocker, Fen Osler Hampson and Pamela Aall (eds), Herding Cats: Multiparty Mediation in a Complex World, 107-133. Washington,

Hope, C., (2006). The marginal impact of CO2 from PAGE2002: an integrated assessment model incorporating the IPCC's five reasons for concerns, Integrated Assessment, 6 (1), 19-56.

Hope, C. \& Newsbury, D. (2009), "Calculating the social cost of carbon", (eds.). Grubb, M, Jamash, Delivering a low-carbon electricity system-technology, economics and policy, pp. 31-63. Cambride University Press, New York. 
Jiang, C., Han., X., Liu, G.,R. \& Liu G., P. (2008), "A Non-Linear Interval Number

Programmes for Uncertain Optimization Problems", European Journal of Operational

Research, 188, 1-13, Elsevier, The Netherlands

Kemp, R., Schot, J. \& Hoogma, R. (1998),'Regime Shifts to Sustainability through Processes of Niche Formation: The Approach of Strategic Niche Management', Technology Analysis and Strategic Management, 10 (2), pp.175-195.

Kemp, R., Rip, A. \& Schot, J. (2001),'Constructing Transition Paths through the Management of Niches' (eds.). Garud R. \& Karnoe, P., Path Dependence and Creation, Mahwah, pp.269-299.NJ: Lawrence Erlbaum Associates Publisgers.

Knetrsch, J., L. (1990), 'Environmental Policy Implications of Disparities between Willingnessto-Pay and Compensation Demanded Measure of Values', Journal of Environmental economics and Management, 18, 227-237.

Knetsch, J., L. (1999),'Evaluation and environmental policies: recent behavioral findings and further implications'. (eds.) Dragun, A.,K. \& Jakobsson, K.M., Sustainability and Global Environmental Policy, Edward Elgar, Cheltenham, UK, pp.193-212.

Kuik, O. \& Gerlagh, R. (2003), 'Trade liberalization and carbon leakage', The Energy Journal, 24, 3, International Association for Energy Economics, USA.

Malerba, F. (2002),'Sectoral Systems of Innovation', Research Policy, 31(2), 247-264.

Nelson, R. R. \& Winter, S.G. (1982). An Evolutionary Theory of Economic Change,Cambridge (MA): Bellknap Press.

Norgaard, R.B. \& Howarth, R.B. (1991), 'Sustainability and Discounting the Future .(ed.) Costanze, R., Ecological Economics,
New York: Colombia Univ.Press.

Rafflsperger C. \& Ticker, J. (1999) (eds.), Protecting Public Health and the Environment: Implementing the precautionary Principle, Washington DC: Island Press, 1999.

Rokeach, M. (1973). The nature of human values, The Free Press, New York.

Rotmans, J., \& Kemp, J., M. van Asselt (2001), 'More Evolution than Revolution: Transition Management in Public Policy', Foresight, 3 (1), 15-31.

Rotmans, J., Grin, J., Schot J. \& Smits, R. (2004), Multi-, Inter- and Transdisciplinary Research Program into Transitions and System Innovations, Maastricht: ICIS.

Shadzli, A. W. and Ahmad Faizul, S. (1992), 'Hybrid wind turbine-diesel power plant in Pulau Layang Layang Spratsly', TNB Report.

Schot, J. (1998). 'The usefulness of evolutionary models for explaining innovation: the case of the Netherlands in the nineteenth century', History and Technology, 14, 173-200.

Schwartz, S. H. \& Bardi, A. (2003). Values and Behavior: Strength and Structure of Relations. Personality and Social Psychology Bulletin, 29, 10: 1207-1220.

Tietenberg, T. (2006), Environmental and Natural Resource Economics, PearsonAddison Wesley, Boston.

Van den Bergh J.C.J.M. \& Bruisma, F.P (2008). Managing the Transition to Renewable Energy- Theory and Practice from Local, Regional and Macro Perspectives, , Edward Elgar, Cheltenham, UK.

Van den Ende, J. \& Kemp, R. (1999),'Technological Transformations in History: How the Computer Regime Grew Out of Existing Regimes', Research Policy, 28, 
833-852.

Von Meier, A. (1994),'Integrating Supple Technologies into Utility Power Systems: Possibilities for Reconfiguratin', in Jane Summeron (ed.), Changing Large Technical systems, pp.211-230, Boulder, San Francisco,Oxford:Westview Press.

Weyant, J. (1999). Energy and Environmental Policy Modelling, Kluwer Academic Publishers, Massachusetts, USA.

Xinhua (2013), 'China Starts Annual South China Sea Fishing Ban’, Xinhua, 16 May 2013.

Zhang, H. (2012). 'China's Evolving Fishing Industry: Implications for Regional and Global Maritime Security', Rajaratnam School of International Studies (RSIS) Working Papers, no.246, Singapore. 